\title{
A Trapping System for the Combined Determination of Total HCN and Total Gas Phase Aldehydes in Cigarette Smoke*
}

\author{
by P. F. Collins, N. M. Sarji, and J. F. Williams \\ Research Department, Liggett and Myers Incorpurated, Durham, N.C., USA
}

\section{INTRODUCTION}

Procedures have previously been described for the automated determination of $\mathrm{HCN}$ and total gas phase aldehydes in cigarette smoke which are practical to use for the analysis of relatively large numbers of cigarettes $(1,2)$. In these procedures, a small tube trap containing a suitable solid absorbent is placed in the smoking train to collect the desired component, with Ascarite $(\mathrm{NaOH}$ on asbestos) being used to trap HCN from whole smoke and activated carbon to trap aldehydes from the gas phase. A disadvantage of these procedures is that a separate smoking is required for each determination since the presence of an Ascarite trap in the system decreases the amount of aldehydes found in the gas phase. Furthermore, some difficulty has been experienced with the $\mathrm{HCN}$ procedure in that results are occasionally obtained which are considerably low apparently due to interferences in the particular lot of Ascarite used. It was therefore of considerable interest to develop a trapping procedure for cigarette smoke which would eliminate the use of Ascarite and would provide suitable samples for the determination of both total $\mathrm{HCN}$ and total gas phase aldehydes.

The possibility of utilizing the gas phase sample solution which is obtained on elution of the activated carbon trap in the aldehydes procedure, together with an extract of the Cambridge pad, as the sample for total HCN determination was initially tried and quite satisfactory results were obtained for the cigarettes tested. This approach was abandoned, however, when it was found that the recovery of $\mathrm{HCN}$ from the activated carbon was dependent on the presence of other gas phase components. In the absence of adsorbed gas phase, less than $50 \%$ of the HCN added to the carbon could be recovered, presenting the possibility that $\mathrm{HCN}$ results might be inaccurately low for cigarettes delivering a low concentration of various gas phase components.

Other solid absorbents were then evaluated, and it was found that a small silica gel trap will efficiently collect both $\mathrm{HCN}$ and aldehydes from the gas phase of at least five cigarettes. These components can be recovered from the silica gel by simple aqueous ex-

\footnotetext{
* Presented, in part, at the CORESTA/TCRC Joint Conference at Williamsburg, Va., October 1972.
}

traction following smoking, with the recovery not being dependent on the presence of other gas phase components. The silica gel extract is then analyzed directly for total aldehydes. In the case of $\mathrm{HCN}$, about half of the total $\mathrm{HCN}$ is present on the Cambridge filter pad, so the silica gel extract is combined with an extract of the filter pad to provide a sample solution for the determination of total HCN. Automated colorimetric systems, slightly modified from those described previously $(1,2)$, are used for analysis of the solutions. Use of this combined procedure, as described in the following sections, results in a considerable saving of time when determinations of both $\mathrm{HCN}$ and total gas phase aldehydes are required, and eliminates the possible inaccuracy associated with the Ascarite procedure.

\section{MATERIALS AND METHODS}

\section{Apparatus}

Smoking System: The smoking machine used in this work is that described by Keith and Newsome (3), and was adjusted with air to provide a 2-second, $35 \mathrm{ml}$ puff once each minute. The trapping system is assembled as shown in Figure 1 . The silica gel trap consists of an $11 \mathrm{~cm}$ length of $9 \mathrm{~mm} \mathrm{i.} \mathrm{d.} \mathrm{glass} \mathrm{tubing} \mathrm{packed}$ with $2.5 \mathrm{~g}$ of silica gel between loose plugs of glass wool and is connected directly to the port of the smoking machine with rubber tubing. Attached to the trap, also with rubber tubing, is a Cambridge filter pad holder with a $44 \mathrm{~mm} \mathrm{CM}-113$ filter pad (pads and holders are available from Phipps and Bird, Inc., Richmond, Virginia). The cigarette is attached to the Cambridge holder with a sleeve of thin latex tubing.

Technicon AutoAnalyzer: The AutoAnalyzer consists of standard modules including a Sampler II, Pump I, and a colorimeter recorder unit with a $15 \mathrm{~mm}$ flowcell, $480 \mathrm{~nm}$ filters for the aldehyde analysis and 540-

Figure 1. Trapping assembly for HCN and aldehydes.

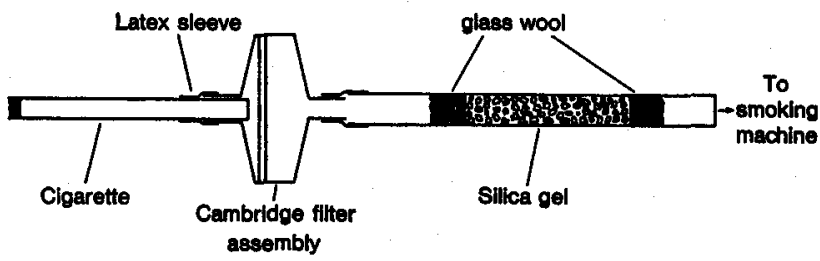


Figure 2. AutoAnalyzer manifold for aldehydes in gas

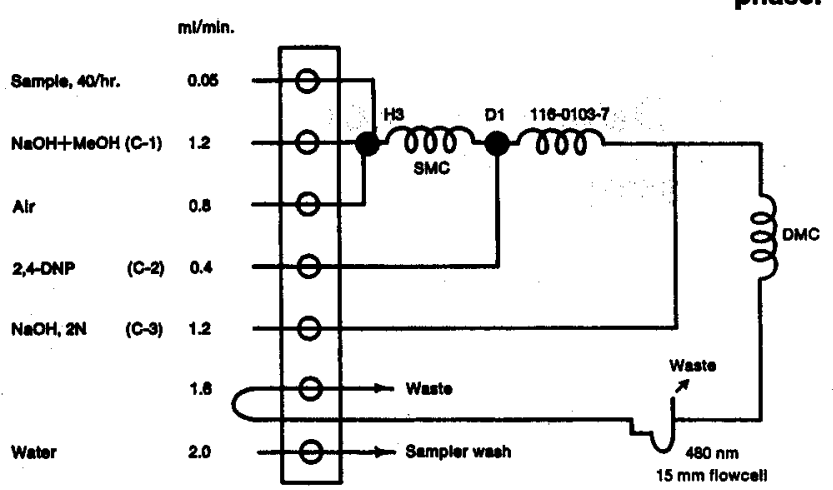

$545 \mathrm{~nm}$ filters for HCN. The manifold for aldehydes is shown in Figure 2; glass is used for transmission lines wherever possible and the $\mathrm{D}_{1}$ fitting is connected directly to the 116-0103-7 mixing coil with sleeving. The HCN manifold is shown in Figure 3. The solution filter in the line leading to the colorimeter consists of a $5 \mathrm{~cm}$ length of a smoking pipe cleaner, of the twisted wire and fiber type, in a $6 \mathrm{~cm}$ length of $4 \mathrm{~mm} \mathrm{i.d}$. glass tubing. The pipe cleaner should be replaced daily.

Figure 3. AutoAnalyzer manifold for HCN in smoke. $\mathrm{ml} / \mathrm{mln}$.

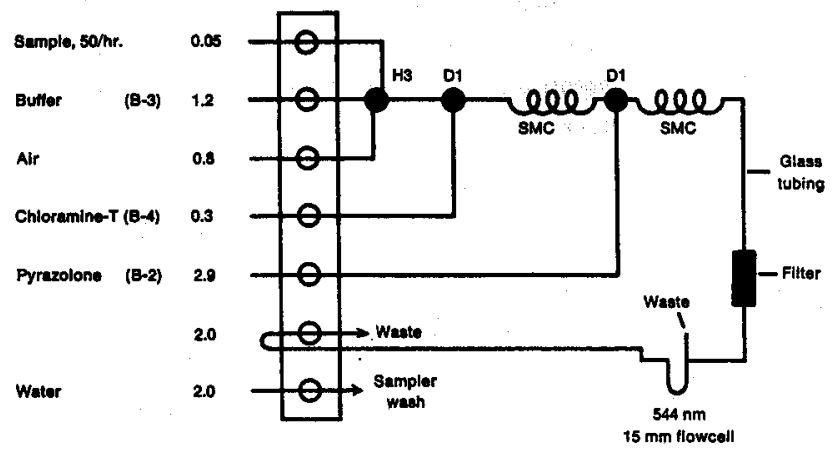

Reagents

\section{A. Reagents required for both determinations}

A-1. Silica gel. Use Davison Grade 408, 12-28 mesh silica gel (available from Fisher Scientific Company as catalog number S-156). Ascertain the moisture content of the material by determining the loss in weight on drying overnight at $150^{\circ} \mathrm{C}$. If this exceeds $1.1 \%$, dry the silica gel by heating at $150^{\circ} \mathrm{C}$ before using.

\section{B. Reagents required for the determination of $H C N$}

B-1. Pyrazolone solution, saturated. Stir $5 \mathrm{~g}$ of $\mathrm{3}^{-}$ methyl-1-phenyl-2-pyrazolin-5-one (Eastman 1397) with 2 liters of water for several hours. Store in a brown bottle.

B-2. Pyridine-pyrazolone solution. Dissolve $0.080 \mathrm{~g}$ of "bis-pyrazolone" (Eastman 6969) in $80 \mathrm{ml}$ of pyridine contained in a brown bottle. About 30 minutes is required for dissolution, and the bottle should be occasionally shaken during this time. When complete solution is obtained, add $400 \mathrm{ml}$ of filtered saturated pyrazolone solution and mix. Prepare the solution fresh each day.

B-3. Buffer. Dissolve $13.6 \mathrm{~g}$ of potassium dihydrogen phosphate and $0.28 \mathrm{~g}$ of disodium hydrogen phosphate in water and dilute to $1000 \mathrm{ml}$. Add $0.5 \mathrm{ml}$ of Brij-35 (Technicon) and mix.

B-4. Chloramine-T, $0.4 \%$. Dissolve $2.0 \mathrm{~g}$ of chloramine- $\mathrm{T}$ (Eastman 1022) in $500 \mathrm{ml}$ of water. Prepare fresh each week.

B-5. Sodium hydroxide solution, $0.625 \mathrm{~N}$. Dissolve $50 \mathrm{~g}$ of $\mathrm{NaOH}$ in about $200 \mathrm{ml}$ of water, cool and dilute to $2000 \mathrm{ml}$.

B-6. Cyanide standards. Prepare a fresh solution equivalent to 250 ppm $\mathrm{HCN}$ by dissolving $0.301 \mathrm{~g}$ of $\mathrm{KCN}$ in water to make $500 \mathrm{ml}$ of solution. Then dilute 0 , 1.0, 2.0, 3.0, 4.0, and $5.0 \mathrm{ml}$ aliquots of this solution each to $100 \mathrm{ml}$ with $50 \mathrm{ml}$ of $0.625 \mathrm{~N} \mathrm{NaOH}$ and water. These working standards are equivalent to 0 , 2.5, 5.0, 7.5, 10.0, and 12.5 ppm $\mathrm{HCN}$ and are $0.312 \mathrm{~N}$ in $\mathrm{NaOH}$. Standards should be prepared fresh every three weeks.

C. Reagents required for the determination of total gas phase aldehydes

C-I. Sodium hydroxide, $0.13 \mathrm{~N}$ in $27 \%$ methanol. Dissolve $5.2 \mathrm{~g}$ of $\mathrm{NaOH}$ in $400 \mathrm{ml}$ of water, add $270 \mathrm{ml}$ of methanol and, after cooling, dilute to $1000 \mathrm{ml}$ with water. Add $0.5 \mathrm{ml}$ of Brij-35 and mix.

C-2. 2,4-Dinitrophenylhydrazine solution. Dissolve $0.396 \mathrm{~g}$ of 2,4-dinitrophenylhydrazine in $100 \mathrm{ml}$ of concentrated hydrochloric acid and $300 \mathrm{ml}$ of water by warming and mixing. Cool to room temperature and dilute to $1000 \mathrm{ml}$ with water.

C-3. Sodium hydroxide, $2 \mathrm{~N}$. Dissolve $80 \mathrm{~g}$ of $\mathrm{NaOH}$ in $800 \mathrm{ml}$ of water, cool and dilute to $1000 \mathrm{ml}$ with water.

C-4. Acetaldehyde standards. Place about $45 \mathrm{ml}$ of water in a $50 \mathrm{ml}$ volumetric flask, stopper, weigh and then cool to about $5^{\circ} \mathrm{C}$. Add, by pipet, $1.0 \mathrm{ml}$ of acetaldehyde (Eastman 468 ) also cooled to about $5^{\circ} \mathrm{C}$. Allow the flask to warm to room temperature, weigh and obtain the weight of added acetaldehyde by difference. Again cool, dilute to volume with water and store at about $5^{\circ} \mathrm{C}$. The approximate concentration of this solution is $16,000 \mathrm{ppm}$ acetaldehyde; calculate the exact concentration from the weight of acetaldehyde taken.

Prepare working standards fresh each week by diluting $4.0 \mathrm{ml}$ of the above solution to $100 \mathrm{ml}$ with water. Then dilute aliquots of this solution of $0,5,10,15,20$, and $25 \mathrm{ml}$ volume each to $100 \mathrm{ml}$ with $\mathrm{H}_{2} \mathrm{O}$. Calculate the exact concentration of these standards which range from 0 to approximately $160 \mathrm{ppm}$ acetaldehyde. The flasks should be kept tightly stoppered to avoid loss of acetaldehyde and may be stored at room temperature for a week.

\section{Procedure}

Smoking of Cigarettes: Cigarettes should be conditioned at $74^{\circ} \mathrm{F}$ and $60 \%$ relative humidity for at least 48 hours before smoking. Mark the cigarettes for the desired butt length; in this work a butt length of tipping paper plus $3 \mathrm{~mm}$ was used.

Pack each tube trap with $2.5 \mathrm{~g}$ of silica gel, tapping the tube to insure tight packing of the granules. Use 
small plugs of glass wool to retain the silica gel in the tube and stopper until used. Assemble the smoking system and smoke five cigarettes through the pad and trap. Take a clearing puff after each cigarette, but do not include these clearing puffs in counting the total number of puffs.

Extraction of Samples: After the smoking is completed, immediately place the Cambridge pad in a $250 \mathrm{ml}$ Erlenmeyer flask containing $100 \mathrm{ml}$ of $0.625 \mathrm{~N} \mathrm{NaOH}$. Stopper and shake the flask very vigorously for about half a minute to disintegrate the pad and allow to stand at least 15 minutes, shaking occasionally. Then clarify a portion of the extract by centrifugation or pouring through glass wool to obtain a solution which can be pipetted. Meanwhile, extract the silica gel trap by emptying the contents including the glass wool plugs into a $125 \mathrm{ml}$ Erlenmeyer flask containing $100 \mathrm{ml}$ of water. Stopper, shake vigorously for about I5 $_{5}$ seconds and then allow to stand with occasional shaking every few minutes. After 30 minutes a portion of the solution may be removed for $\mathrm{HCN}$ analysis, and after a total of 60 minutes extraction, the solution may be analyzed for total aldehydes.

Automated HCN Analysis: Proceed with the HCN analysis as soon as possible after extraction of the traps. Prepare the mixed extract solution by pipetting $4.0 \mathrm{ml}$ of the pad extract into a test tube and then add $4.0 \mathrm{ml}$ of the corresponding silica gel extract. Mix and stopper the tube until used. Operate the AutoAnalyzer in the normal manner and pump reagents through the system until a stable baseline is obtained. Place duplicate cups of each mixed extract solution on the turntable with single cups of standards at the beginning and end. Operate the sampler at a rate not exceeding 50 samples per hour with a $2: 1$ sample to wash ratio. At the completion of the run, construct a calibration curve relating ppm of $\mathrm{HCN}$ to average peak height with the data obtained from the standards. Read the ppm of $\mathrm{HCN}$ for each sample and calculate the micrograms of $\mathrm{HCN}$ per puff.

$$
\mu \mathrm{g} \mathrm{HCN} / \text { puff }=\frac{\text { ppm } \mathrm{HCN} \times 200}{\text { no. of puffs }}
$$

Automated Aldehyde Analysis: The AutoAnalyzer with manifold assembled as shown in Figure 2 is operated in the normal manner using a sample rate not exceeding 40 per hour with a $2: 1$ sample to wash ratio. Pump reagents until a stable baseline is obtained, then run duplicate cups of the silica gel extracts with single cups of the standards at the beginning and end. Load only six cups on the turntable at a time since acetaldehyde is quite volatile and a significant amount would be lost from the sample cups on prolonged standing, even though covered with the sampler cover plate. At the completion of the run, construct a calibration curve relating average peak height to ppm acetaldehyde and read the ppm of acetaldehyde for each sample. Calculate the micrograms per puff of total gas phase aldehydes, expressed as acetaldehyde:

$$
\mu \mathrm{g} / \mathrm{puff}=\frac{\mathrm{ppm} \times 100}{\text { no. of puffs }}
$$

\section{RESULTS AND DISCUSSION}

The ability of the silica gel trap to collect aldehydes and HCN from the gas phase of cigarette smoke was evaluated by smoking five $85 \mathrm{~mm}$ cigarettes without filter by the described procedure except for inclusion of a second trap to collect the components not trapped by the silica gel. An activated carbon trap was used to collect any escaping aldehydes and analysis of the carbon eluate indicated that the silica gel had trapped at least $99 \%$ of the total aldehydes. When checking the efficiency of the silica gel for trapping $\mathrm{HCN}$, the second trap contained sodium hydroxide pellets which had been found in other work to be an efficient absorber for gas phase $\mathrm{HCN}$. Analysis of the $\mathrm{NaOH}$ trap indicated that no $\mathrm{HCN}$ had escaped the silica gel. Thus, silica gel is seen to be an efficient adsorber for both gas phase aldehydes and HCN.

The use of $2.5 \mathrm{~g}$ of silica gel provides a considerable excess for the trapping of these gas phase components from 5 cigarettes as shown by an experiment in which the normal trap was preceded by a trap containing only $1.0 \mathrm{~g}$ of silica gel. Analysis of the traps indicated that the $1.0 \mathrm{~g}$ of silica gel was adequate for trapping inasmuch as neither $\mathrm{HCN}$ or aldehydes were found in the second trap.

The silica gel which was used in this investigation was material as received from the manufacturer with a moisture content of $1.1 \%$ as determined by the loss in weight on drying overnight at $150^{\circ} \mathrm{C}$. It was of interest to ascertain if the moisture content of the silica gel has an effect on results for $\mathrm{HCN}$ and total aldehydes so an experiment was carried out to compare results found using silica gel containing $0.1,1.1$ and $21.6 \%$ moisture. The different moisture levels were obtained by either drying at $150^{\circ} \mathrm{C}$ or allowing the silica gel to become humidified by standing open in the air. Four ports of $85 \mathrm{~mm}$ cigarettes without filter were smoked using each silica gel. Analysis of the silica gel extracts, diluted with an equal volume of $0.625 \mathrm{~N} \mathrm{NaOH}$ for the $\mathrm{HCN}$ determination, gave results as shown in Table $\mathrm{I}$. The averages obtained for gas phase $\mathrm{HCN}$ or aldehydes using the silica gels containing 0.1 and $1.1 \%$ moisture are not significantly different (t-test, 0.05 level of significance) but the results with the humidified silica gel are considerably low. It is therefore important to ascertain the moisture content of the silica gel before use and, if excessive, to dry the material to a moisture content not exceeding $1 . x \%$.

Table 1. Effect of molsture content of silica gel on the HCN and total aldehydes found.

\begin{tabular}{c|c|c}
\hline \multirow{2}{*}{$\begin{array}{c}\text { \% Moisture } \\
\text { in silica gel }\end{array}$} & \multicolumn{2}{|c}{$\mu$ Ave. } \\
& $\mathrm{HCN}^{* \star}$ & Total aldehydes \\
\hline 0.1 & 22.3 & 191.0 \\
1.1 & 22.7 & 191.5 \\
21.6 & 7.6 & 161.5 \\
\hline
\end{tabular}

- Each value is an average for 4 ports or 20 cigarettes.

* Represents HCN found only on the silica gel trap. 
The use of a trap between the cigarette and smoking machine will cause the actual puff volume to be different from that to which the smoking machine is adjusted with air, by whatever volume of gas phase is adsorbed by the trap. This factor had been ignored in the development of the previous procedures $(1,2)$ and estimates of the magnitude of this effect have now been made for traps containing silica gel, CAL activated carbon, and Ascarite. Since the accurate measurement of puff volume during smoking appears rather difficult, an indirect method of measurement was used to obtain the estimates. Cigarettes were smoked through only a Cambridge pad using a single port syringe-type smoking machine adjusted to provide a $35.0 \mathrm{ml}$ puff. The volume of the gas phase exhausted on each cycle of the smoking machine was measured using a soapfilm manometer. With no trap in the exhaust line, the exhaust volume averaged $34.9 \mathrm{ml}$. When a trap was placed in the exhaust line so that the gas phase passed through the trapping material before volume measurement, an appreciable decrease in volume was found. The percent adsorption of gas phase by the trap, averaged for five cigarettes per trap, was used to estimate the actual puff volume obtained when the trap is positioned normally between the cigarette and smoking machine, with the machine adjusted with air to give a $35 \mathrm{ml}$ puff. The data obtained are summarized in Table 2. It can be seen that traps containing silica gel or activated carbon adsorb about $3 \%$ of the gas phase, thereby increasing the puff volume by about one $\mathrm{ml}$. This appears reasonable in view of our estimate that about $4 \%$ of the gas phase volume consists of vapors other than the permanent gases and $\mathrm{CO}_{2}$. While activated carbon might be expected to be a better adsorber for many of these components, silica gel should remove more of the water vapor due to its efficient desiccative properties. In the case of Ascarite traps, the puff volume is increased by $2 \mathrm{ml}$ and this is probably due mainly to partial absorption of $\mathrm{CO}_{2}$ which is generally present to the extent of $9 \%$ or more by volume in gas phase of smoke.

The effect of the silica gel trap on puff volume was found to be fairly constant for the various types of filter cigarettes tested and this makes it feasible to correct for the effect, if desired, by simple adjustment of the smoking machine. Based on the data presented, if the smoking machine is adjusted to provide a $34.0 \mathrm{ml}$

Table 2. Effect of varlous trapping materlals on puff volume.

\begin{tabular}{|c|c|c|c|}
\hline $\begin{array}{l}\text { Trapping } \\
\text { material }\end{array}$ & Filter type* & $\begin{array}{c}\% \text { Gas } \\
\text { phase } \\
\text { adsorbed }\end{array}$ & $\begin{array}{l}\text { Estimated } \\
\text { ave. puff } \\
\text { volume** }\end{array}$ \\
\hline Sillca gel & Cellulose acetate & 3.1 & 36.1 \\
\hline Silica gel & $\begin{array}{l}\text { Carbon + cellulose } \\
\text { acetate }\end{array}$ & 3.1 & 36.1 \\
\hline Silica gel & $\begin{array}{l}\text { Perforated, carbon + } \\
\text { cellulose acetate }\end{array}$ & 2.7 & 36.0 \\
\hline $\begin{array}{l}\text { CAL carbon } \\
\text { Ascarite }\end{array}$ & $\begin{array}{l}\text { Cellulose acetate } \\
\text { Cellulose acetate }\end{array}$ & $\begin{array}{l}2.6 \\
5.4\end{array}$ & $\begin{array}{l}35.9 \\
37.0\end{array}$ \\
\hline
\end{tabular}

- All clgarettes were commerical $85 \mathrm{~mm}$ brands.

*" With the smoking machine adjusted to a $35.0 \mathrm{ml}$ puff with air. puff with no trap in the system, then the actual puff volume when the trap is used should adequately approximate the standard $35 \mathrm{ml}$ puff volume. However, if the exact puff volume is critical to the study or if significantly different smoking products are to be tested, it is recommended that the effect of the silica gel trap on puff volume be determined with the cigarette studied.

The effectiveness of simple aqueous extraction in recovering the trapped $\mathrm{HCN}$ and aldehydes from the silica gel was studied by placing mixtures of acetaldehyde or HCN in air on silica gel traps, and after standing about 15 minutes, proceeding with the extraction and analysis. The actual concentration of the gas mixtures was determined concurrently by dispensing an equal volume of the gas into an evacuated flask containing water, and after standing to allow absorption of the component by the water, proceeding with the analysis in the same manner as with a trap extract. For the HCN analysis; the solutions were diluted with an equal volume of $0.625 \mathrm{~N} \mathrm{NaOH}$. The amount of $\mathrm{HCN}$ placed on each trap was $1136 \mu \mathrm{g}$ and recovery averaged $101 \%$ for three traps. Recovery of $5950 \mu \mathrm{g}$ of acetaldehyde placed on three other traps also averaged $101 \%$.

The rate of extraction of $\mathrm{HCN}$ from the Cambridge pad and of $\mathrm{HCN}$ and total aldehydes from the silica gel traps using manual, intermittent shaking was studied using pads and traps obtained from the smoking of 3 ports of $85 \mathrm{~mm}$ cigarettes without filter. Portions of the extracts were analyzed after various extraction times with average results as shown graphically in Figure 4. Extraction of $\mathrm{HCN}$ from the silica gel reaches a maximum within 30 minutes whereas extraction of aldehydes is somewhat slower, attaining the maximum at 60 minutes. As directed in the procedure, an aliquot of the silica gel extract is removed after 30 minutes extraction for HCN analysis, but this introduces only a very small error in the aldehyde

Figure 4. Rate of extraction of HCN and aldehydes from traps.

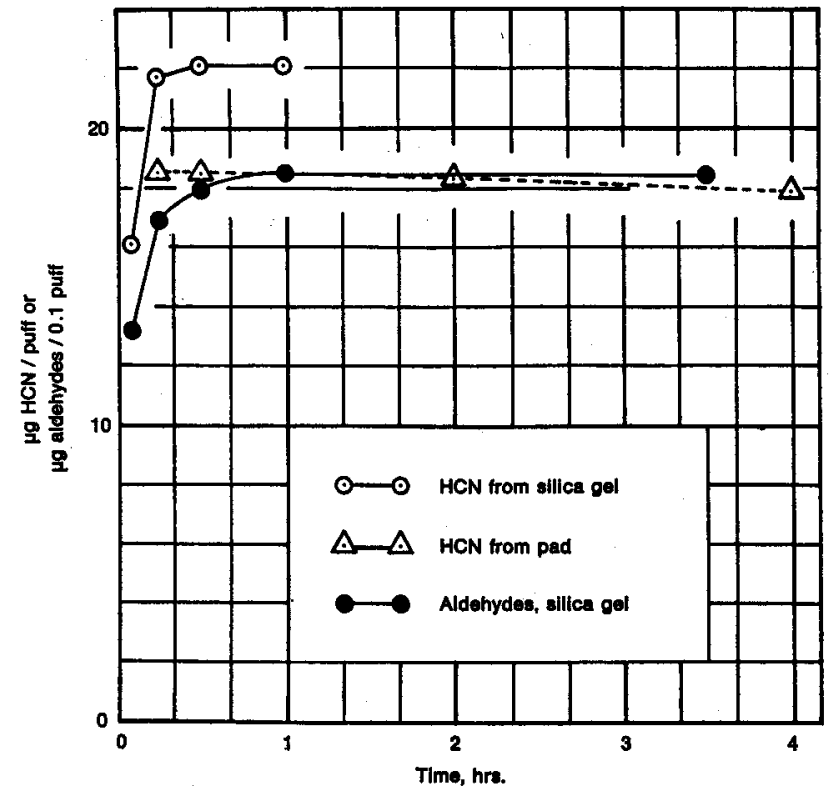


Table 3. Recovery of acetaldehyde added to sillica gel extracts.

\begin{tabular}{|c|c|c|c|c|}
\hline \multirow{2}{*}{ Smoke type } & \multicolumn{3}{|c|}{$\mu g$ Acetaldehyde/puff } & \multirow{2}{*}{$\begin{array}{c}\% \\
\text { Recovery } \\
\text { of add }\end{array}$} \\
\hline & Initial & Added & Found & \\
\hline $\begin{array}{l}\text { Carbon + cellulose } \\
\text { acetate filtered } \\
\text { Cellulose }\end{array}$ & 101.5 & 161.7 & 260.2 & 98 \\
\hline $\begin{array}{l}\text { acetate filtered } \\
\text { Non-filtered } \\
\text { Non-filtered }\end{array}$ & $\begin{array}{l}142.5 \\
164.9 \\
163.8\end{array}$ & $\begin{array}{l}161.7 \\
165.8 \\
165.8\end{array}$ & $\begin{array}{l}296.2 \\
331.1 \\
330.0\end{array}$ & $\begin{array}{r}95 \\
100 \\
100\end{array}$ \\
\hline
\end{tabular}

determination since only about $3 \%$ of the total aldehydes are extracted after the initial 30-minute period. The ability to recover the gas phase components from the silica gel trap by simple aqueous extraction is considered a definite improvement over the previous total aldehyde procedure wherein elution of the carbon trap with methanol is required.

The automated procedures utilized for both determinations are very similar to those described previously $(1,2)$ with a few modifications as to pump tube sizes and reagent composition. In the $\mathrm{HCN}$ manifold, a rather high noise level had been occasionally encountered which is apparently due to particulate material in the stream flowing into the colorimeter. Attempts to eliminate this difficulty through changes in the reagents have been unsuccessful but the simple filter now used overcomes the noise problem without greatly affecting the level of sample interaction.

The adequacy of these automated procedures was evaluated through recovery tests in which a solution of acetaldehyde or potassium cyanide was added to sample extract solutions. The results of these tests are summarized in Tables 3 and 4. Recovery of the added acetaldehyde averaged $98 \%$ while recovery of added cyanide averaged $97 \%$

The stability of the aldehydes in the silica gel extract and of HCN in both Cambridge pad and silica gel extracts have been examined using samples from the
Table 4. Recovery of cyanide added to combined silica gel + Cambridge pad extracts.

\begin{tabular}{l|c|c|c|c}
\hline \multicolumn{1}{c|}{ Smoke type } & \multicolumn{3}{c|}{$\mu \mathrm{g} \mathrm{HCN} /$ puff } & $\begin{array}{c}\% \\
\text { Recovery } \\
\text { of add }\end{array}$ \\
& Initial & Added & Found & \\
\hline $\begin{array}{l}\text { Carbon + cellulose } \\
\text { acetate filtered }\end{array}$ & 18.36 & 30.00 & 47.65 & 98 \\
$\begin{array}{l}\text { Cellulose } \\
\text { acetate filtered }\end{array}$ & 33.08 & 29.27 & 60.86 & 95 \\
$\begin{array}{l}\text { Non-filtered } \\
\text { Non-filtered }\end{array}$ & 42.24 & 33.33 & 74.60 & 97 \\
\hline
\end{tabular}

smoking of $85 \mathrm{~mm}$ cigarettes without filter. The least stable was the $\mathrm{HCN}$ in the pad extract where a $3 \%$ loss occurred on standing for 4 hours increasing to a $19 \%$ loss on continued standing overnight. The silica gel extracts were considerably more stable, showing only a $5 \%$ loss of HCN and no loss of total aldehydes on standing overnight. From these results, it is apparent that the extracts should be analyzed for $\mathrm{HCN}$ as soon as possible after smoking and certainly on the same day, while the aldehyde analysis can be delayed until the following day, if desired.

Various cigarette samples have been analyzed by this procedure to obtain information as to precision and also to compare results to those by other procedures. For total gas phase aldehydes, the other procedure chosen for comparison was that previously described using activated carbon as the gas phase trap. The results are summarized in Table 5, and it can be seen that the two methods give results in good agreement, with differences in averages for any sample not exceeding $5 \%$. The pooled standard deviation calculated from the individual results by the silica gel procedure was $5.4 \mu \mathrm{g}$ of aldehydes per puff for a single port of five cigarettes.

In the case of $\mathrm{HCN}$, the other method chosen for comparative purposes is one in which pelleted sodium hydroxide is used to trap gas phase $\mathrm{HCN}$ and, following smoking, the trap contents and Cambridge pad are combined to provide a composite solution for automated

Table 5. Results for total gas phase aldehydes by sillica gel and activated carbon procedures.

\begin{tabular}{|c|c|c|c|c|c|}
\hline \multirow{2}{*}{ Cigarette description } & \multirow{2}{*}{ Smoking condition } & \multicolumn{2}{|c|}{ Total aldehydes, $\mu \mathrm{g} /$ puff* $^{\star}$} & \multirow{2}{*}{$\underset{\%}{\text { Difference }}$} & \multirow{2}{*}{$\begin{array}{l}\text { R.S.D., } \% \\
\text { Sillica gel }\end{array}$} \\
\hline & & Silica gel & Activated C & & \\
\hline $\begin{array}{l}\text { Brand A, } 85 \mathrm{~mm} \text { with cellulose } \\
\text { acetate + granular carbon filter }\end{array}$ & $\begin{array}{l}\text { With filter } \\
\text { Without filter }\end{array}$ & $\begin{array}{l}120.7(8.1) \\
194.7(8.0)\end{array}$ & $\begin{array}{l}124.2(8.0) \\
185.7(8.2)\end{array}$ & $\begin{array}{r}-2.8 \\
+4.8\end{array}$ & $\begin{array}{l}5.5 \\
2.9\end{array}$ \\
\hline $\begin{array}{l}\text { Brand } \mathrm{B}, 85 \mathrm{~mm} \text { with } \\
\text { cellulose acetate filter }\end{array}$ & $\begin{array}{l}\text { With filter } \\
\text { Without filter }\end{array}$ & $\begin{array}{l}161.7(8.2) \\
187.7(7.8)\end{array}$ & $\begin{array}{l}164.6(8.1) \\
185.0(8.1)\end{array}$ & $\begin{array}{r}-1.8 \\
+1.5\end{array}$ & $\begin{array}{l}1.9 \\
3.0\end{array}$ \\
\hline
\end{tabular}

* Each value is the average of 5 or 6 ports of 5 cigarettes per port. Nu mbers in parentheses are the average number of puffs per cigarette.

- Difference of the average by silica gel as compared to the average by the CAL activated carbon procedure.

*.* Relative standard deviation for a single port of 5 clgarettes.

Table 6. Results for total HCN in smoke by silica gel and NaOH trapping procedures.

\begin{tabular}{|c|c|c|c|c|c|}
\hline \multirow{2}{*}{ Cigarette description } & \multirow{2}{*}{ Smoking condition } & \multicolumn{2}{|c|}{ Total HCN, $\mu \mathrm{g} /$ puff* } & \multirow{2}{*}{$\begin{array}{c}\text { Difference }^{* *} \\
\%\end{array}$} & \multirow{2}{*}{$\begin{array}{l}\text { R.S.D., } \% 0^{* * *} \\
\text { silica gel }\end{array}$} \\
\hline & & Silica gel & $\mathrm{NaOH}$ & & \\
\hline $\begin{array}{l}\text { Brand } A, 85 \mathrm{~mm} \text { with cellulose } \\
\text { acetate }+ \text { granular carbon filter }\end{array}$ & $\begin{array}{l}\text { With filter } \\
\text { Without filter }\end{array}$ & $\begin{array}{l}17.1(8.0) \\
37.6(7.9)\end{array}$ & $\begin{array}{l}15.8(7.9) \\
38.7(7.9)\end{array}$ & $\begin{array}{l}+8.2 \\
-2.8\end{array}$ & $\begin{array}{l}8.4 \\
2.6\end{array}$ \\
\hline $\begin{array}{l}\text { Brand } \mathrm{B}, 85 \mathrm{~mm} \text { with } \\
\text { cellulose acetate filter }\end{array}$ & $\begin{array}{l}\text { With filter } \\
\text { Without filter }\end{array}$ & $\begin{array}{l}31.2(8.2) \\
38.8(7.9)\end{array}$ & $\begin{array}{l}33.3(8.1) \\
37.9(7.7)\end{array}$ & $\begin{array}{l}-6.3 \\
+2.4\end{array}$ & $\begin{array}{l}3.0 \\
3.5\end{array}$ \\
\hline
\end{tabular}

- Each value is the average of 5 or 6 ports of 5 cigarettes per port. Numbers in parentheses are the average number of puffs per cigarette.

** Difference of the average by silica gel compared to the average by the $\mathrm{NaOH}$ procedure.

*** Relative standard deviation for a single port of 5 cigarettes. 
$\mathrm{HCN}$ analysis. This procedure was used instead of the Ascarite method as it had been found in other work to adequately trap $\mathrm{HCN}$ and to yield more reproducible results. In Table 6 are summarized the data for various samples, and it is seen that the methods give results in quite good agreement. The pooled standard deviation calculated from the individual results by the silica gel procedure was $1.2 \mu \mathrm{g}$ of $\mathrm{HCN}$ per puff for a single port of 5 cigarettes.

On the basis of the information and results obtained in this investigation, it is concluded that the silica gel trapping procedure yields reliable results for total gas phase aldehydes which are essentially equivalent to those by the activated carbon procedure and the simplicity of that procedure is retained. The smoke samples obtained are also adequate for the determination of total $\mathrm{HCN}$, giving results which are considered more reliable than those by the Ascarite procedure.

\section{SUMMARY}

A procedure for the combined defermination of total $\mathrm{HCN}$ and total gas phase aldehydes in cigarette smoke has been developed which is practical to use for the analysis of relatively large cigarette samples. The smoking system includes a Cambridge pad for collection of the particulate phase and a small tube of silica gel to trap gas phase components, with 5 cigarettes being smoked through each pad and trap. Following smoking, the Cambridge pad and silica gel trap are extracted; the silica gel extract is used for the determination of total gas phase aldehydes and the combined extracts for $\mathrm{HCN}$ analysis. Colorimetric procedures, automated through use of the Technicon AutoAnalyzer as described previously, are employed for the analysis of the sample extracts.

Evaluation of this combined procedure indicates that it yields reliable results for both total $\mathrm{HCN}$ and total gas phase aldehydes with greater speed and ease of operation than provided by the previously described methods. The procedure has been applied to various cigarette samples with the relative standard deviation for a single port of 5 cigarettes ranging from 1.9 to $5.5 \%$ for gas phase aldehydes and from 2.6 to $8.4 \%$ for total HCN.

\section{ZUSAMMENFASSUNG}

Die Autoren entwickelten ein Verfahren zur kombinierten Bestimmung von Gesamtcyanwasserstoff (HCN) und den Gesamtgasphasenaldehyden in Cigarettenrauch, das sich gut für die Untersuchung von verhältnismäßig umfangreichen Cigarettenproben eignet. Das Abrauchsystem umfaBt einen Cambridge-Filter zur Erfassung der Partikelphase und eine kleine Kieselgel-Falle zum Auffangen der Gasphasenbestandteile, wobei jeweils fünf Cigaretten pro Filter und Falle verraucht werden. Nach dem Abrauchen werden beide Auffangvorrichtungen extrahiert; der Kieselgelextrakt wird für die Bestimmung der Gesamtaldehyde der Gasphase und beide Extrakte zusammen für die Bestimmung des Cyanwasserstoffes benutzt. Für die Analysen der Extrakte werden kolorimetrische Verfahren angewendet, die entsprechend früherer Veröffentlichungen der Autoren unter Einsatz des Tednicon AutoAnalyzers automatisch arbeiten.

Das beschriebene Kombinationsverfahren hat sich bei der Bestimmung sowohl von Gesamtcyanwasserstoff als auch von den Gesamtaldehyden der Gasphase als zuverlässig erwiesen; der Analysenvorgang nimmt außerdem weniger Zeit in Anspruch und ist einfacher zu handhaben als früher beschriebene Verfahren. Die Anwendung der Methode bei verschiedenen Cigarettenproben ergab bei einem Rauchkopf für fünf Cigaretten einen Variationskoeffizienten von 1,9 bis $5,5 \%$ für die Aldehyde der Gasphase und von 2,6 bis $8,4 \%$ für Gesamtcyanwasserstoff.

\section{RESUME}

On a développé une méthode permettant la détermination combinée de l'HCN total et des aldéhydes totaux de la phase gazeuse dans la fumée de cigarette, ce procédé étant d'un usage pratique pour l'analyse d'assez grands échantillons de cigarettes. Le système à fumer consiste en un filtre Cambridge qui collecte la phase particulaire et en un tube mince de silica gel qui piège les composants de la phase gazeuse, ceci pour 5 cigarettes fumées dans chaque filtre et chaque piège. Après que celles-ci sont fumées, on extrait le filtre Cambridge et le piège en silica gel; on emploie l'extrait en silica gel pour l'analyse des aldéhydes totaux de la phase gazeuse et les extraits combinés pour l'analyse de 1 'HCN. On emploie des procédés colorimétriques, automatisés grâce au «Technicon AutoAnalyzer» déjà décrit antérieurement, pour l'analyse des extraits.

L'evaluation de ce procédé combiné indique qu'il recèle des résultats valables aussi bien pour l'HCN total que pour les aldéhydes totaux de la phase gazeuse, et ceci d'une manière plus rapide et plus aisée que celle fournie par les méthodes décrites précédemment. Le procédé a été appliqué à différents échantillons de cigarettes montrant, pour un lot individuel de 5 cigarettes, une déviation standard relative de $x, 9$ à $5,5 \%$ pour les aldéhydes de la phase gazeuse et de 2,6 à $8,4 \%$ pour $l^{\prime} \mathrm{HCN}$ total.

\section{REFERENCES}

1. Collins, P. F., N. M. Sarji, W. W. Lawrence, and J. F. Williams: An automated method for the determination of total aldehydes in gas phase of cigarette smoke; Tobacco Science 14 (1970) 182-186.

2. Collins, P. F., N. M. Sarji, and J. F. Williams: An automated method for determination of hydrogen cyanide in cigarette smoke; Tobacco Science 14 (x970) $x_{2}-x 5$.

3. Keith, C. H., and J. R. Newsome: Quantitative studies on cigarette smoke, I: An automated smoking madtine; Tobacco Science I (1957) 51-57.

The authors' address:

Liggett and Myers Incorporated, Research Department, Durham, N.C., 27702, USA. 